\title{
National Food and Nutrition Security System (SAMAT), a Tool for Identifying and Monitoring Food Insecurity in the Country
}

\author{
Masoomeh Gholami ${ }^{1}$, Majid Najafzadeh ${ }^{1}$, Naser Behnampour ${ }^{1}$, Zahra Abdollahi ${ }^{2}$, Farzaneh Sadeghi \\ Ghotbabadi $^{2}$, Farhad Lashkarboluki ${ }^{1}$, Mohammad Reza Honarvar ${ }^{1 *}$
}

1. Health Management and Social Development research Center, Golestan University of Medical Sciences, Gorgan, Iran.

2. Nutrition Department Ministry of Health and Medical Education Tehran, Iran.

Article Type:

Original Article

Article History:

Received: 8 Jun 2019

Revised: 30 Jul 2019

Accepted: 19 Aug 2019

\section{*Correspondence:}

Mohammad Reza

Honarvar,

Health Management and

Social Development

research Center, Golestan

University of Medical

Sciences, Gorgan, Iran mrhonarvar@goums.ac.ir

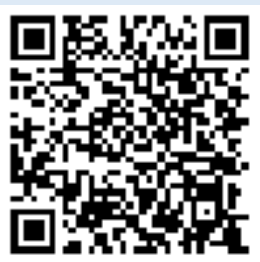

\begin{abstract}
Background and objectives: Iran was reported in the high-risk group of World Food Security Map in 2008 .Identifying food insecurity is first step for executing interventions. Measuring household food security is its cornerstone. SAMAT System was designed to provide a variety of GIS-based reports to policy makers and managers in the field of food security.
\end{abstract}

Methods: SAMAT system was developed by a team working with various specialties. The system was analyzed using Rational Unified Process methodology and after optimization and normalization process, centralized database was formed. SQL Server 2014 software was used for its implementation. SharpMap open source engine was used to render spatial data and display maps on the web, and many parts of the engine were coded specifically to meet different organizational needs. The system was designed using the WEB GIS engine.

Results: SAMAT system was executed in nine provinces of the country in different periods. SAMAT dashboard provides a variety of information for executive managers. Based on demographic data, the state of food insecurity can be identified at different levels from city to village, in a variety of graphs. A spectrum from the urban distribution to the local distribution of food insecurity can be identified on the GIS map. Zooming in on different areas can help to identify more food insecure neighborhoods within the village or town, thus giving managers the priority of food insecurity interventions at the neighborhood or village level. One can view household characteristics and the results of questionnaire information.

Conclusion: AMAT system can be useful for managing food security at the national, provincial, city and even rural or urban levels. we recommend periodically prioritizing points, Identifying the provinces and re-evaluating the effectiveness of interventions through the SAMAT-based system after comprehensive implementation of food insecurity reduction

Keywords: Nutritional Status, Software, Geographic Information Systems, Food Supply.

Copyright $@$ 2018, Jorjani Biomedicine Journal has published this work as an open access article under the terms of the Creative Commons Attribution License (http://creativecommons.org/licenses/by-nc/4.0/) which permits noncommercial uses of the work while it is properly cited. 


\section{Introduction}

With the rise of the concept of human development around the world, the issue of food security has been of particular interest in the last decade. The State of Food Security and Nutrition in the World (SOFI) is an annual flagship report jointly prepared by Food and Agricultural Organization (FAO), IFAD, UNICEF, WFP and WHO to inform on progress towards ending hunger, achieving food security and improving nutrition and to provide in-depth analysis on key challenges for achieving this goal in the context of the 2030 Agenda for Sustainable Development (1). Food insecurity, with its extensive and profound effects on the individual and the family life, is rooted in poverty. The number of people with food deficiency worldwide has increased since 2014 and reached 821 million in 2017 (2). Given to importance of food insecurity, it has been included in Sustainable Development Goals (SDG 2.1.2). In 2008, the United Nations released the World Food Security Map. Iran was reported in this classification in the high-risk group. Various studies estimate the prevalence of food insecurity in Iran to be 36 to 44 percent (3-6).

Identifying and improving food insecurity are very important for many governments and policy makers. Measuring household food security is its cornerstone $(7,8)$. Household Food Insecurity Access Scale (HFIAS) Questionnaire is a simple and useful tool that is designed and proposed by the FAO and Food and Nutrition Technical Assistance (FANTA) to measure household food insecurity (9). The HFIAS is designed as a simple and fast-track solution based on the basic notion $t$, food insecurity is "a measurable, descriptive and analytical experience" for measuring food security access. The validity and reliability of this tool has been evaluated in developing countries including Iran (10). The questionnaire does not directly address nutrition quality but rather covers household perceptions of changes in food quality regardless of the actual composition of the food. This questionnaire has 9 specific questions. By dividing the values, values 0 and 1 mean safe state, values 2 to 7 mean mild insecurity, values 8 to 14 mean moderate insecurity, and values 15 to 27 mean severe insecurity. Ordered by the Ministry of Health Office of Nutrition Improvement, the SAMAT System was designed by the Golestan University of Medical Sciences. Currently, information from several provinces and counties based on the HFIAS has been recorded in this system and provides a variety of Geographic Information Based (GIS)-based reports to policy makers and managers in the field of food security.

\section{Materials and Methods}

National Food and Nutrition Security System (SAMAT) was developed as a result of team working performed by various specialties in nutrition, health, health management and information technology (IT) and Geographic information system (GIS). In this system, data were collected by trained surveyors from rural and urban household (preferably the mother of the family) and the results were recorded. Because this system was under development, the first interviews registered in paper forms and then the data were converted to software formats, but in second and third phases all interviews registered via tablet directly during survey.

A separate Global Positioning System (GPS) was provided for each questionnaire to mark the information of each household and recorded in the GIS map model. The GIS map reveals how food insecurity is distributed. 
Standard baseline maps were used to determine the distribution and scattering of food insecurity in different layers of the province including cities, rural areas and residents of natural resources. Food insecurity information was attached to rural areas in the form of Attribute Tables and was identified on the map based on the classification of food insecurity severity with different color intensities on the map. An independent webbased system was developed to transfer this information over the Internet or intranet platform. The system was designed using the WEB GIS engine so that the speed of information, transfer and management was high and managers could use the visual representation of the data on the map to plan and make decisions. The design of this system has led to the optimization of the system to improve registration and use of information. In this system, each of the organizational levels, based on the definition of accessibility to information, have access to different segments, and other options embedded in SAMAT are location-based and statistical reporting capability in standard formats such as Excel or Shape file for transferring data to ArcGIS environment which is very useful for future analysis. The system was analyzed using Rational Unified Process (RUP) methodology for production of the system. After optimization and normalization process, centralized database was formed. SQL Server 2014 software was used for its implementation. The ASP.Net MVC Web Design Pattern was main engine, while the programming languages were the $\mathrm{C} \#$.Net for server-side and the JavaScript for client-side. Leaflet.js open source JavaScript Library was used to render spatial data and display maps on the web, and many parts of the engine were coded specifically to meet different organizational needs. A variety of common methods as well as internal hosts were used for software security.

\section{Results}

The SAMAT and interface software were designed to input data into Android systems. The system was executed in nine provinces of the country in different periods (Table 1). At first it was conducted in Golestan province for 4677 households. After presentation of its results to the Ministry of Health, second version of SAMAT was designed for 7 most food insecure provinces according to Sampat report (11). Thereafter Office of Nutrition Improvement of Ministry of Health ordered designing of 3rd version of SAMAT for 11449 families in south Khorasan province.

In Golestan province, 4677 households were evaluated and their questionnaire information was entered in SAMAT system. An information dashboard was designed to be accessible for managers. According to the order of Ministry of Health's office of Nutrition Improvement, the SAMAT system was implemented in 7 cities out of 7 food insecure provinces (Figure 1). A total of 3,059 household food insecurity data were entered into the system, and the results were provided to intervention teams for food insecurity reduction. 
Table 1: Provinces and Specific Sample Size of Each Province in SAMAT System

\begin{tabular}{|l|l|l|}
\hline \multicolumn{1}{|c|}{ 1th version of SAMAT } & \multicolumn{1}{|c|}{ 2th version of SAMAT } & \multicolumn{1}{|c|}{ 3rd version of SAMAT } \\
\hline Golestan province & $\begin{array}{l}\text { 7 Districts from most Food } \\
\text { insecure Provinces }\end{array}$ & South Khorasan Province \\
\hline $\begin{array}{l}\text { Questioners used GPS for } \\
\text { positioning }\end{array}$ & $\begin{array}{l}\text { Questioners used an android } \\
\text { software for data entry and } \\
\text { positioning }\end{array}$ & $\begin{array}{l}\text { Questioners used an android } \\
\text { software for data entry and } \\
\text { positioning }\end{array}$ \\
\hline Sample size: 4677 Families & Sample size: 30059 Families & Sample size: 11449 Families \\
\hline
\end{tabular}

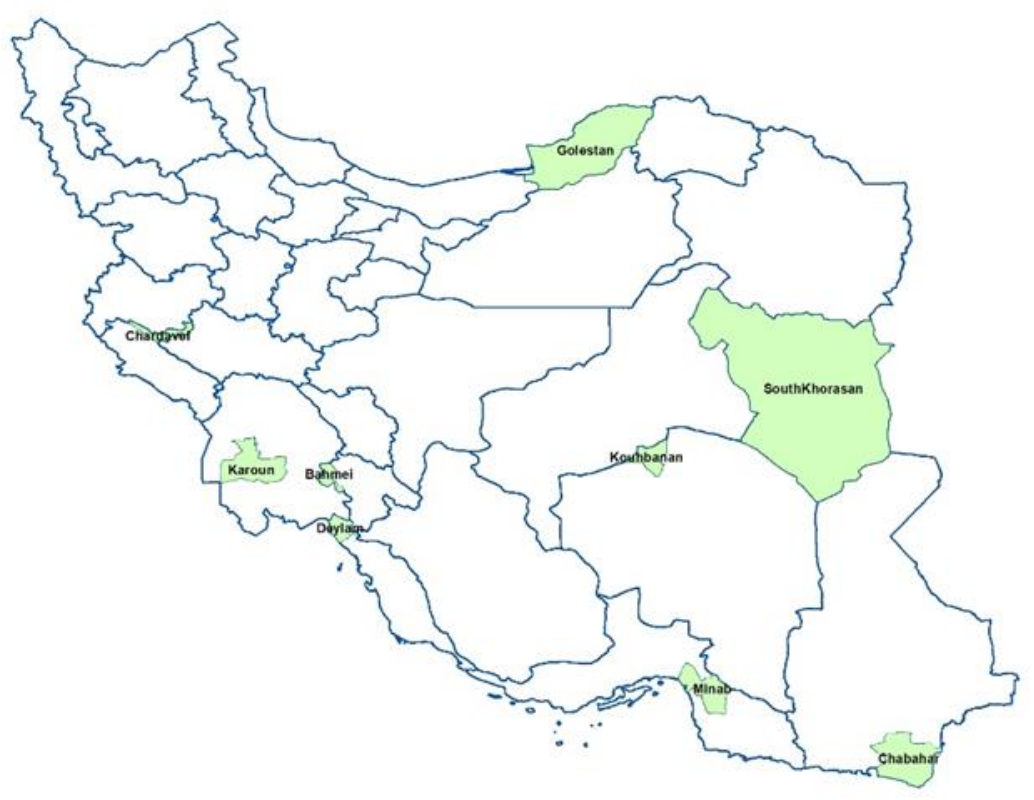

Figure 1: The provinces where the SAMAT was executed

Various reports can be extracted from the SAMAT system. Impact of some demographic factors on the severity of food insecurity can be extracted from the system.
Figure 2 shows the relationship of household head literacy status with the severity of food insecurity in South Khorasan. 


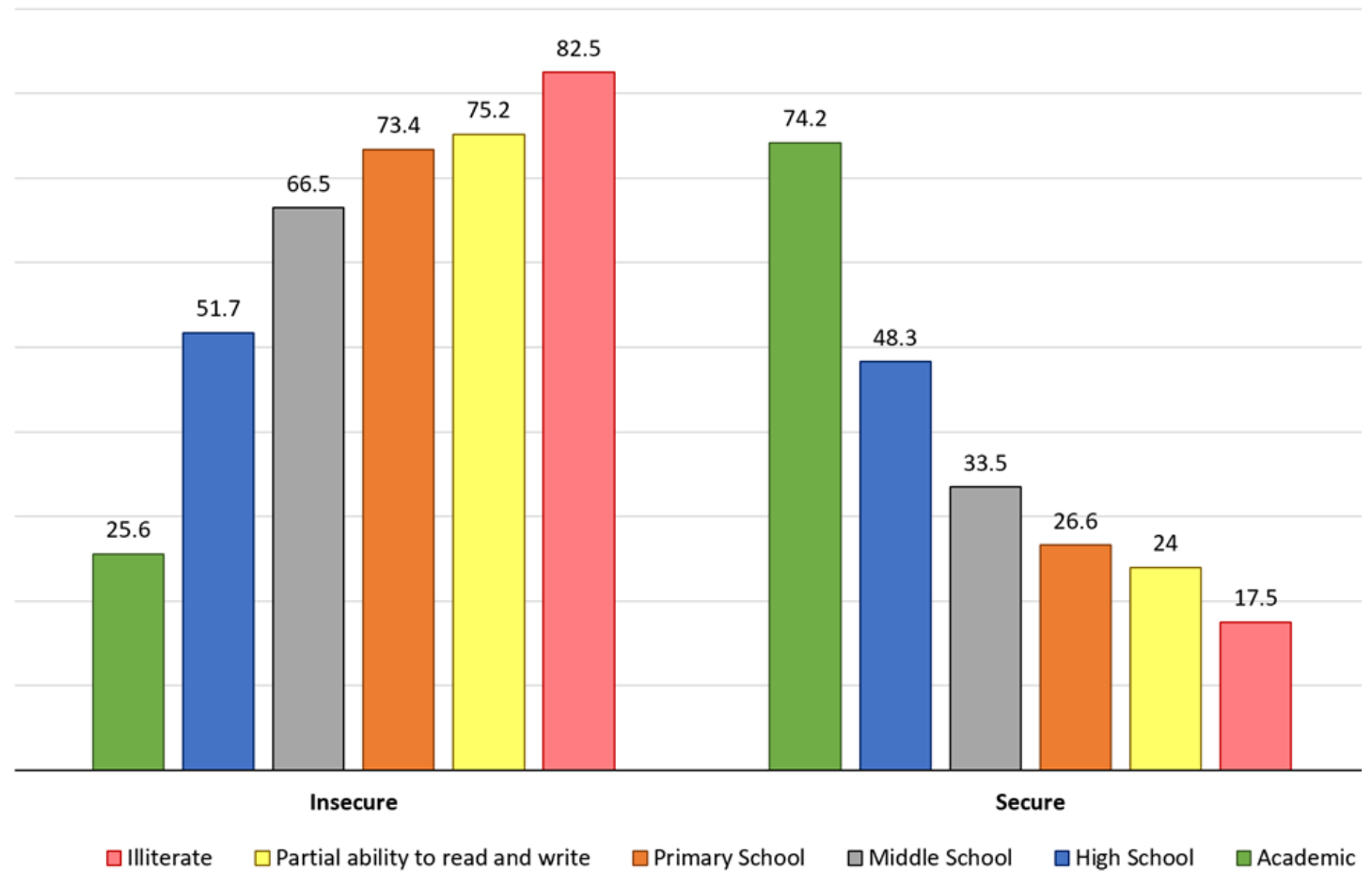

Figure 2: The association of household head level education on food security situation in South Khorasan in 2017 in SAMAT system

The SAMAT dashboard provides a variety of information for executive managers. Based on demographic data, the state of food insecurity can be identified at different levels from city to village, showing by different graphs. By using this system, a spectrum of distribution information could be gathered in different geographic areas which can be identified on the GIS map. Zooming on different areas can help to identify more food insecure neighborhoods within the villages or cities.
Thereby managers could prioritize the necessary interventions within specific areas. Further on the map one can identify food insecure households and view household characteristics and the results of questionnaire information (Figure 3). It is only possible for managers to view household information from the food insecurity management system, so household information is not shared with others. 


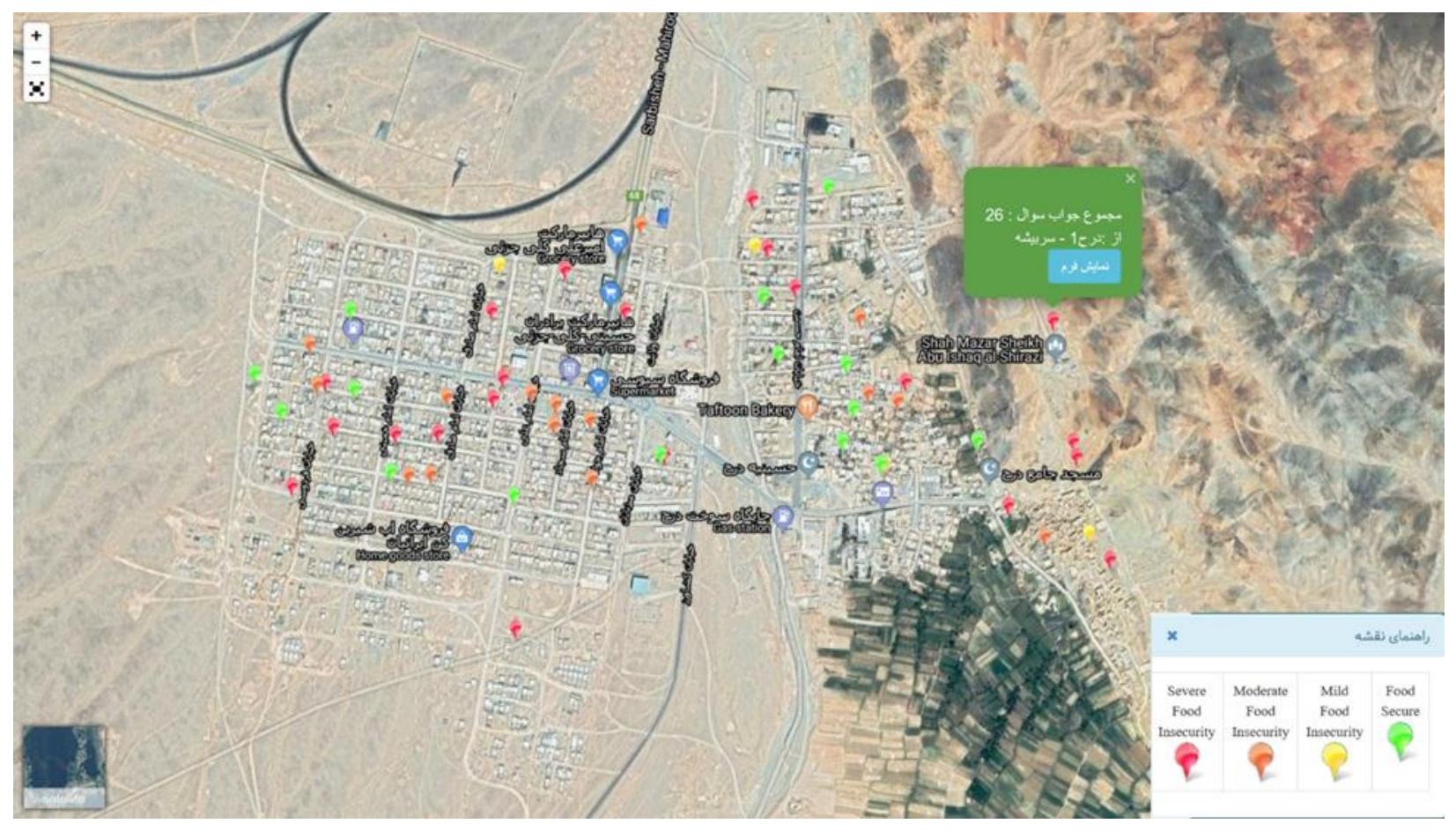

Figure 3. Distribution map of household food insecurity up to neighborhood and household level in SAMAT system

\section{Discussion}

As study shows, SAMAT could apply the food insecurity data to the GIS and facilitate decision making for appropriate interventions. This information can identify the location of food insecurity and vulnerable groups as well as their geographical areas. A wide range of food and food insecurity data can be added to the baseline maps. These systems can put a lot of information into simple formats for decision makers to use (12).

GIS approaches through spatial analysis models can help assess food insecurity, determine food accessing areas, and other factors affecting food accessibility. To determine the environmental factors affecting food access and a variety of spatial measurements for food security, McEntee and Agyeman investigated the GIS methods used for food safety analysis through reviewing literature. According to the GIS-based approach in rural Vermont, they were able to determine areas of poor geographical access to food, food deserts, locating food vendors, residential units and roads and distance from food retailers using ArcGIS software (13). Ghirardelli and coworkers used GIS data from 68 low-income neighborhoods in California (14). In Iran we tried to design SAMAT system based on similar appraches.

According to the Food Insecurity and Vulnerability Information and Mapping systems (FIVIMS) initiative, maps derived from GIS-based data can provide visual information about demographic groups and food insecurity situations. Based on maps and related information, many intervention strategies can be proposed and shared among policy makers (12).One of the goals of the FIVIMS initiative by FAO and international 
organizations was to improve access to food insecurity information through networking and sharing (15). There are a lot of experience in implementing FIVIMS in different countries such as Guatemala, Namibia, Angola, Bangladesh Burkina Faso and India (16). In order to design of SAMAT and using HFIAS, we tried to follow FAO instructions about FIVIMS. Visualization of reports and simplicity of working with its features especially for policy makers and managers were one of our approaches in SAMAT. The World Food Program proposes a system similar to FIVIMS, called food safety monitoring systems (FSMS) to quickly inform decision-makers about food and nutrition processes and identify food insecure places or the possibility of moving some areas to food insecure situations (17). This system also uses geographical data.

There are many experiments about using geographical data and computer or mobile systems. Harry and colleagues used a mobile food program (mFR) to monitor populations, educate consumers, health professionals and policymakers, and influence diet recommendations (18). Using an open source Android application (the SATIDA COLLECT application) conducted in the Central African Republic, population assessment and GISbased data loading was simple and feasible (19). Smith and his colleagues in the United Kingdom produced household food insecurity risk maps based on household type. In this way, the information sources were transferred to GIS maps after validation and statistical analysis.(20). This approach is similar to us in SAMAT, except that population can not use the system. Using SAMAT is only for managers and policy makers.

Sometimes the system has been designed for combatting diseases, for example LitJeh Lim and colleagues introduced an electronic Nutrition Information System (NIS) to help distribute food to fight HIV. NIS had four main aspects in design. Modular system design, database design including hierarchical nature of table design, relational database design, data model and user-interface and network design. NIS is now helping to support the 30,000 people fed in Kenya weekly (21). For SAMAT we have similar design aspects.

Availability and accessibility to food and nutrients are important components in food security. Using the Global Positioning System (GPS) data, Shearer and coworkers investigated the relationship between food location availability and accessibility with variables affecting dietary intake. Using GIS techniques, they generated information on changes in food availability and accessibility (22).

The use of new tools and technologies for rapid access to accurate information is crucial for analyzing food insecurity and making decisions for timely and effective interventions. As we know, international organizations recommend the use of these systems and there are numerous experiences in the world. Due to the structure of Iran, and according to our practices, SAMAT system can be one of these suitable systems that can help policy makers and managers to identify food insecure areas and to follow the results of interventions. 


\section{Conclusion}

The SAMAT system has so far collected information from nine provinces in Iran. This system allows managers to design interventions at the household level, village or even city level, to identify food insecurity interventions and to implement necessary interventions and aggregate intervention information at the regional level. Given the capabilities of the SAMAT system in recognizing food insecurity and its contributing factors, it can be a useful tool for managing food insecurity at the national, provincial, urban and rural levels, therefore we recommend periodic prioritization of the goals, Identifying food insecurity within the provinces and re-evaluating the effectiveness of interventions through the SAMAT-based system after comprehensive implementation of food insecurity reduction interventions. The National Planning and Management Organization, along with agencies involved in food insecurity reduction, including the Ministry of Interior, the Ministry of Health and the Ministry of Welfare, will set a country-based food insecurity paradigm based on the SAMAT system and support comprehensive food insecurity interventions. The SAMAT system will monitor the results of the interventions.

\section{Authors' contributions}

All authors contributed equally to this work. 


\section{References}

1. FAO I, WFP W, UNICEF. The state of food security and nutrition in the world 2019: safeguarding against economic slowdowns and downturns. 2019;

2. fao.org. SOFI 2018 - The State of Food Security and Nutrition in the World [Internet]. www.fao.org. [cited 2018 Oct 1]. Available from: http://www.fao.org/state-of-food-securitynutrition/en/

3. payab M, Dorosty Motlagh A, Eshraghian M, Siassi F, karimi T. The association between food insecurity, socio-economic factors and dietary intake in mothers having primary school children living in Ray 2010. Iran J Nutr Sci Food Technol Vol 7 No 1 Spring 2012. :75-84. [DOI:10.1186/2251-6581-12-21]

4. Mohammadzadeh A, Dorosty AR, Eshraghian MR. Household Food Security Status and Food Consumption among High School Students in Esfahan, Iran. Iran J Epidemiol. 2011 Jun 15;7(1):38-43.

5. Ramesh T, Dorosty Motlagh AR, Abdollahi M. Prevalence of household food insecurity in the City of Shiraz and its association with socioeconomic and demographic factors, 2008. Iran J Nutr Sci Food Technol. 2010 Jan 10;4(4):53-64.

6. Dastgiri S, Mahboob S, Tutunchi $\mathrm{H}$, Ostadrahimi A. Determinants of Food Insecurity: A Cross - Sectional Study in Tabriz. J Ardabil Univ Med Sci. 2006 Sep 15;6(3):233-9.

7. Headey D, Ecker O. Rethinking the measurement of food security: from first principles to best practice. Food Secur. 2013 Jun 1;5(3):327-43. [DOI:10.1007/s12571-013-0253-0]

8. Pérez-Escamilla R, Gubert MB, Rogers B, Hromi-Fiedler A. Food security measurement and governance: Assessment of the usefulness of diverse food insecurity indicators for policy makers. Glob Food Secur. 2017 Sep 1;14:96-104. [DOI:10.1016/j.gfs.2017.06.003]
9. Coates J, Swindale A, Bilinsky P. Household Food Insecurity Access Scale (HFIAS) for measurement of food access: indicator guide. Wash DC Food Nutr Tech Assist Proj Acad Educ Dev. 2007; [DOI:10.1037/e576842013-001]

10. MOHAMMADI F, OMIDVAR N, HARRISON GG, GHAZI-TABATABAEI M, ABDOLLAHI M, HOUSHIAR-RAD A, et al. Is Household Food Insecurity Associated with Overweight/Obesity in Women? Iran J Public Health. 2013 Apr 1;42(4):380-90.

11. Kolahdoz F, Najafi F. The National Food and Nutrition Security Monitoring System in Iran and the First National Food Security Scenarios Mapping Survey (Sampat Research). Ministry of Health and Medical Education.2001.[in Persian].

12. COMMITTEE ON WORLD FOOD SECURITY: 24th Session - GUIDELINES FOR NATIONAL FOOD INSECURITY AND VULNERABILITY INFORMATION AND MAPPING SYSTEMS (FIVIMS): BACKGROUND AND PRINCIPLES [Internet]. [cited 2019 Sep 26]. Available from: http://www.fao.org/3/W8500e/W8500e.htm\#E10 E21

13. McEntee J, Agyeman J. Towards the development of a GIS method for identifying rural food deserts: Geographic access in Vermont, USA. Appl Geogr. 2010 Jan;30(1):165-76. [DOI:10.1016/j.apgeog.2009.05.004]

14. Ghirardelli A, Quinn V, Foerster SB. Using Geographic Information Systems and Local Food Store Data in California's Low-Income Neighborhoods to Inform Community Initiatives and Resources. Am J Public Health. 2010 Nov;100(11):2156-62. [DOI:10.2105/AJPH.2010.192757]

15. fivims [Internet]. [cited 2019 Sep 26]. Available from: http://www.fao.org/FOCUS/E/SOFI/fiv-e.htm

16. National FIVIMS - Updates from Selected Countries [Internet]. [cited 2019 Sep 26]. 
Available from:

http://www.fao.org/3/X6726E/x6726e02.htm

17. Food Security Monitoring Systems (FSMS) Technical Guidance Sheet | World Food Programme [Internet]. [cited 2019 Sep 19]. Available from: https://www.wfp.org/publications/monitoringfood-security-technical-guidance-sheet

18. Harray AJ, Boushey CJ, Pollard CM, Delp EJ, Ahmad Z, Dhaliwal SS, et al. A Novel Dietary Assessment Method to Measure a Healthy and Sustainable Diet Using the Mobile Food Record: Protocol and Methodology. Nutrients. 2015 Jul 3;7(7):5375-95. [DOI:10.3390/nu7075226]

19. Enenkel M, See L, Karner M, Álvarez M, Rogenhofer E, Baraldès-Vallverdú C, et al. Food Security Monitoring via Mobile Data Collection and Remote Sensing: Results from the Central African Republic. PloS One. 2015;10(11):e0142030.

[DOI:10.1371/journal.pone.0142030]
20. Smith D, Thompson C, Harland K, Parker S, Shelton N. Identifying populations and areas at greatest risk of household food insecurity in England. Appl Geogr Sevenoaks Engl. 2018 Feb;91:21-31.

\section{[DOI:10.1016/j.apgeog.2017.12.022]}

21. Lim JL, Yih Y, Gichunge C, Tierney WM, Le TH, Zhang J, et al. The AMPATH Nutritional Information System: designing a food distribution electronic record system in rural Kenya. J Am Med Inform Assoc JAMIA. 2009 Dec;16(6):8828. [DOI:10.1197/jamia.M3139]

22. Shearer C, Rainham D, Blanchard C, Dummer T, Lyons R, Kirk S. Measuring food availability and accessibility among adolescents: Moving beyond the neighbourhood boundary. Soc Sci Med. $2015 \quad$ May;133:322-30. [DOI:10.1016/j.socscimed.2014.11.019]

\section{How to cite:}

Gholami M, Najafzadeh M, Behnampour N, Abdollahi Z, Sadeghi Ghotbabadi F, Lashkarboluki F, Honarvar M.R. National Food and Nutrition Security System (SAMAT), A Tool for Identifying and Monitoring Food Insecurity in the Country. Jorjani Biomedicine Journal. 2019; 7(3): 24-33. 